\title{
Mecânica Analítica: um livro-texto moderno para cursos de graduação em Física
}

\author{
H. Fleming ${ }^{1}$ \\ Instituto de Física, Universidade de São Paulo
}

O professor Nivaldo Agostinho Lemos, conhecido físico teórico brasileiro, tem se dedicado, há anos, também ao aprimoramento do ensino científico de nível superior, sendo já ampla a lista de trabalhos que publicou, por exemplo, no renomado ( e exigente!) American Journal of Physics. Há algum tempo li um artigo seu, nessa revista, em que uma elegante demonstração da identidade de Jacobi para os parênteses de Poisson era apresentada. Conjecturei: deve vir aí um livro de mecânica do Nivaldo. De fato, ei-lo, publicado pela Editora Livraria da Física, que, aliás, vem sendo pródiga produtora de excelentes textos científicos (Mecânica Analítica, pp $388,2004)$.

O nome Mecânica Analítica remonta a Lagrange, e vinha sendo abandonado pelos autores modernos em favor de Mecânica Clássica, ou simplesmente Mecânica, ou, ainda, no caso do singular e excelente livro de Giovanni Gallavotti, Meccanica Elementare (ao menos no original italiano). Aliás, folheando-se a Meccanica Elementare de Gallavotti, a primeira pergunta que surge, espontânea, é: o que será uma Meccanica Avanzata?

Aplaudo a escolha do autor. No mínimo, ele pode apresentar, sem maiores explicações, a importante observação de Einstein $A s$ equações da mecânica analítica têm um significado que excede em muito o da mecânica newtoniana, que está, em epígrafe, no seu Capítulo 7.

O ensino da mecânica analítica foi marcado, nos anos 50, pelo aparecimento do excelente Classical mechanics, de Goldstein, e por uma tomada de posição que está bem claramente expressa no prefácio dessa obra:classical mechanics affords the student an opportunity to master many of the mathematical techniques necessary for quantum mechanics while still working in terms of the familiar concepts of classical physics. No contexto do prefácio ficava claro que era necessário apresentar justificativas para um segundo curso de mecânica, e esta era apenas a de uma preparação para a mecânica quântica. Lembro-me ainda da irritação que a frase causou ao professor Silvio Ferraz Mello, então no início de sua brilhante carreira de especialista na Mecânica Celeste.

Hoje esta posição é insustentável: os grandes avanços no estudo da estabilidade, do caos, dos sistemas integráveis, a

${ }^{1}$ Enviar correspondência para H.Fleming. E-mail:fleming @if.usp.br . generalização do formalismo hamiltoniano descoberta por Dirac, são áreas da mecânica onde se realiza pesquisa de ponta, e de extrema importância. Ao mesmo tempo, e em consequiência, houve necessidade de uma nova geração de textos de mecânica. Não podemos deixar de mencionar, nesta nova geração, a notável Mecânica Clássica Moderna, de Walter Wreszinski, que, grosso modo, começa onde Nivaldo termina.

O que coloca a Mecânica Analítica de Nivaldo Lemos nesta nova geração é a ênfase em simetrias, com um belo tratamento do teorema de Emmy Noether, o tratamento moderno das transformações canônicas, que introduz a notação simplética, um tratamento elementar do teorema KAM e o formalismo de Dirac para o tratamento, no formalismo canônico, de sistemas vinculados.

Excetuados estes assuntos, o livro tem um conteúdo semelhante ao da primeira edição do livro de Goldstein: formalismo lagrangeano, princípio de Hamilton, corpos rígidos, pequenas oscilações, mecânica relativística, formalismo hamiltoniano, transformações canônicas, teoria de Hamilton-Jacobi, teoria clássica dos campos.

Mas o livro não é só isso, e nem principalmente isso. Em primeiro lugar, é uma obra que irá certamente agradar aos estudantes, e não só aos professores. Não há capítulo que não se beneficie do vasto know-how do autor, leitor e contribuinte assíduo do já citado American Journal of Physics, sobre novas e melhores demonstrações dos resultados clássicos. Um grande número de exemplos, e exercícios, muito dos quais completamente resolvidos, apresentam o lado concreto dos abstratos formalismos. Oportunas e iluminantes citações chamam a atenção para pontos especialmente importantes. Notas históricas, na medida certa, fornecem perpectiva ao leitor iniciante.

O meu capítulo favorito é o oitavo, Transformações Canônicas, que apresenta um tratamento único do formalismo dos parênteses de Poisson. Numa perspectiva wigneriana da física, onde o substrato mais essencial é o conjunto das simetrias que o espaço e o tempo devem ter para que uma teoria formulada sobre eles nos seja aceitável, eles representam, no contexto da mecânica

Copyright by the Sociedade Brasileira de Física. Printed in Brazil. 
clássica, a álgebra de Lie do grupo de transformações da relatividade de Galileu. Por isso sobevivem, quase imutados, na mecânica quântica não relativísitica, e são a base, no formalismo de Dirac, da conexão mecânica clássica-mecânica quântica.

Neste capítulo, talvez o resultado mais bonito de Nivaldo: a demonstração, quase sem cálculos, de que os parênteses de Poisson satisfazem a identidade de Jacobi, e, assim, formam uma álgebra de Lie. O autor mostra que, a partir do fato de que os parênteses de
Poisson são invariantes por transformações canônicas, segue que as identidades de Jacobi devem ser satisfeitas. Minha leitura preferida deste resultado é: se não forem satisfeitas as identidades de Jacobi, os parênteses de Poisson não têm um significado invariante, o que ressalta a importância das identidades de Jacobi.

Ficarei muito surpreso se este magnífico texto não se tornar a referência padrão dos cursos de mecânica analítica nos países de língua portuguêsa. 